\title{
Construindo a legitimidade: reflexões sobre as transformações das práticas de militância no movimento sindical
}

Kimi Tomizaki * e M aurício Rombaldi **

Resumo: 0 eixo central deste estudo reside na tentativa de responder a questões sobre as mediações existentes no estabelecimento dos vínculos de engajamento de trabalhadores no movimento sindical, bem como sobreasformas assumidas por processos delegitimação política no interior dedistintas esferas do campo sindical brasileiro. Paratanto, parte-sedos casos dedois sindicatos, ambos do Estado deSão Paulo: o Sindicato dos M etalúrgicos do ABC eo Sindicato deTelecomunicações. Entreas semelhanças existentes entreesses sindicatos, sobressai o fato de que durantea década de 1990 ambos passaram por processos dereestruturação produtiva em seus setores; a concomitante renovação de quadros sindicais - em que se destacam sucessões geracionais; e, por fim, a semelhança deorigem social de trabalhadores esindicalistas entre os setores - em grande parte de migrantes nordestinos com baixa escolaridade e ausência de qual ificação profissional. Sobreas diferenças, observa-se quea constituição dos processos de legitimação sindical assumedistintas composições, o queresulta em diversasreações aos processos detransformação vivenciadosnos dois setores. Ainda queatravessando transformações sociais homólogas, ossindicatos permitem observar dinâmicas próprias na construção dediferentes legitimidades militantes eno destino desindicalistas.

Palavras-chave: sindicatos; legitimidade; trajetória social; campo político; telecomunicações; metalurgia.

Building legitimacy: reflections on the changes in political militancy practices in the union movement

Abstract: This study is focused on theattempt to answer questions about the mechanismsfor the commitment of workers to political union activity, as well as about the way the political legitimacy process occurs in different spheres of the Brazilian trade union field. In order to answer such questions, two unionsfrom the state of São Paulo werestudied: thesteelworkers' union, from the $A B C$ region, and thetelecommunications workers' union. Thereare some similarities between these unions, especially the fact that during the 90 s, both of them went

\footnotetext{
* Professora de Sociologia da Faculdade de Educação da Universidade de São Paulo (FE-USP), São Paulo, Brasil.kimi@usp.br

* Doutorando do Departamento de Sociologia da Faculdade de Filosofia, Letras e Ciências Humanas da USP (FFLCH-USP), São Paulo, Brasil. mauricio.rombaldi@gmail.com
} 
through the processes of economic restructuration and personnel renewal- including generational succession. It is also interesting to mention the similarity concerning the social origin of workersand tradeunionists, mostly $\mathrm{N}$ ortheastern unskilled migrants with low schooling levels. Concerning the differences between theworkers, we observethat the constitution of the process of trade union legitimacy takes on distinct compositions, which result in distinct reactions to the changes in the two sectors. Even though they have faced equivalent social changes, each of these unions has its own different dynamics in the building of different militant legitimacies and in future unionists' actions.

Key words: tradeunions; legitimacy; social route; political field; telecommunications; steel work.

Introdução

"Na verdade não se fabrica militantes, né? Militante nasce feito!"

(Diretor de base do Sindicato dos Metalúrgicos do $A B C$, São Bernardo do Campo, 2002)

"O sindicalismo está no sangue, vem de familia." (Dirigente sindical do Sindicato dos Trabalhadores em Telecomunicações de São Paulo, 2006)

Talvez fosse justo dizer que este artigo surge da percepção, um tanto quanto incômoda, por parte de seus autores, de que, diferentemente de outras pesquisas que assumem como objeto de estudo as práticas de grupos que militam politicamente, as pesquisas sobre sindicalismo no Brasil parecem desconsiderar em suas análises os processos por meio dos quais os indivíduos se engajam e se mantêm como lideranças no interior do movimento sindical. D e forma que este texto foi concebido como um exercício intelectual que pretende analisar os processos de ordem objetiva e subjetiva - que possibilitam a determinados indivíduos tornarem-se militantes e constitui rem uma situação de legitimidade que sustenta sua posição de liderança em dois importantes sindicatos brasileiros.

$\mathrm{N}$ esse sentido, é preciso esclarecer que essa perspectiva de análise não deve ser interpretada como uma posição subjetivista do mundo social que ignoraria o efeito que as estruturas objetivas exercem sobre a formação de esquemas mentais e a ação dos indivíduos. Pelo contrário, a compreensão da organização interna de determinados espaços sociais e das posições ocupadas em seu interior exige o conhecimento teórico e prático sobre os mecanismos sociais e históricos dos quais os indivíduos são produto. (Bourdieu, 1992).

Para materializar essa proposta, partiremos da principal constatação dos estudos sobre o mundo sindical nas últimas décadas: no Brasil e no mundo, observa-se uma crescente tendência de diminuição tanto dos índices de 
sindicalização como do poder sindical em termos de mobilização e de capacidade de negociação com governos e patronato. Grosso modo, a interpretação de tal fenômeno tem se materializado em duas tendências analíticas no interior da literatura sociológica: de um lado, podemos identificar estudos que vislumbram um processo de decadência irreversível para o sindicalismo (Rodrigues, 1999); de outro, encontram-se inúmeros estudos que tendem a interpretar que o movimento sindical mundial estaria enfrentando os reflexos de uma crise conjuntural. (Ramalho; Santana, 2003; Rodrigues, 2001). De qualquer maneira, é possível observar que, comumente, ambas as correntes tendem a privilegiar em suas análises alguns aspectos da ação sindical: (i) as estratégias empreendidas pelos sindicatos frente ao patronato - do "uso" de greves às práticas de negociação; (ii) o conteúdo das pautas de negociação e dos acordos coletivos; (iii) o aumento ou a diminuição das conquistas em termos salariais ou de garantia de direitos trabalhistas e/ou relacionados a novas características do emprego - como, por exemplo, a flexibilização dos contratos de trabalho.

$\mathrm{N}$ este artigo, pretendemos realizar um deslocamento no foco da análise sobre as transformações observadas no movimento sindical, tendo em vista constituir um quadro analítico capaz de apreender e explicar os processos de formação e reformulação das práticas das lideranças sindicais. D ito de outra forma, as reflexões que se seguirão buscam não assumir os sindicatos como instituições coerentes e homogêneas, cujas ações possam ser assumidas como objetos de análise em si, sem que se leve em conta os atores que as produziram e o espaço social e político no qual eles estão inseridos ${ }^{1}$. A exemplo do estudo feito por Bernard Pudal sobre o Partido Comunista Francês, entende-se aqui que 0 sindicato não pode ser pensado como uma coisa, nem coisas sucessivas, mas como "o produto objetivado de uma prática incessantemente em jogo". (Pudal, 1989). Sendo assim, as alterações ocorridas no mundo sindical serão submetidas a uma reflexão que, menos do que descrever e analisar as alterações das estratégias institucionais dos sindicatos, tem como objetivo central restituir a textura e a produção do laço invisível que associa os agentes nessa cooperação concorrencial que é o engajamento político.

0 trabalho sindical, como todo trabalho ligado ao campo político, constitui uma ação instável que requer um aprendizado do conjunto de regras de

I. Pode-se observar que, de maneira geral, ainda que os estudos chamados "descritivistas" não assumam filiações teóricas com teorias tais como a da ação racional (ver OLSON, Mancur. A lógica da ação coletiva: os benefícios públicos e uma teoria dos grupos sociais. São Paulo: Edusp, 1999), a crítica válida para esta perspectiva também acaba voltando-se contra tais estudos: não se pode ignorar o fato de que variáveis de nível contextual ou subjetivo estejam presentes na lógica da ação de grupos sociais. Entre elas, destaca-se: os níveis de coesão grupal, a força ideológica, a conjuntura política, os níveis de insatisfação, etc. 
funcionamento desse campo específico. Pode-se dizer que o acúmulo de aprendizagens específicas conjugadas a certas características pessoais dos sindicalistas constitui uma espécie de capital militante e político², que permite ao seu detentor ocupar um espaço legítimo no interior da entidade da qual participa. (Canedo, 1991, 1998, 2002; O fferlé, 1999). M as é preciso sublinhar que os "conteúdos" que compõem essa posição de legitimidade podem ser alterados por transformações mais amplas que atingem os espaços políticos - tais como as mudanças na ordem econômica mundial ou nacional - , o que exige novas aprendizagens dos seus participantes. Em outras palavras, a instabilidade do campo político, sobretudo em momentos de profundas alterações sociais, econômicas e políticas, como a última década para o sindicalismo brasileiro, pode conduzir a uma situação em que os sindicalistas perdem o domínio sobre as condições de funcionamento do próprio campo sindical. Tal situação apresentaria novos desafios àqueles que se dedicam a esse trabalho, "empurrando-os" a redefinir suas formas de ação para continuar a ocupar a mesma posição. (Cf: Wagner, 2004, 2005).

N esse sentido, conduziremos nossas reflexões a partir de uma questão-chave no interior do espaço político: a constituição da legitimidade. N ossa hipótese é a de que a construção de uma situação de legitimidade que faz com que um sindicalista se reconheça e seja reconhecido como um autêntico representante da sua categoria se sustenta sobre duas lógicas singulares, mas co-dependentes: (i) os atributos pessoais - o que inclui sua origem e sua trajetória social; e (ii) as práticas e os discursos que eles são capazes de formular e reformular ao longo de sua carreira. Tendo em vista articular essas duas lógicas com os processos de engajamento político e constituição da situação de liderança, daremos ênfase a algumas fases específicas da trajetória dos sindicalistas, quais sejam; o recrutamento para o movimento sindical; 0 aprendizado das práticas e dos discursos, e, finalmente, as situações de estabelecimento ou de exclusão no jogo político.

I sso será realizado por meio da análise das configurações históricas da prática militante no interior de dois sindicatos brasileiros: o Sindicato dos

2. Em que pese o fato de que o debate em torno desses dois conceitos ainda está em andamento, neste trabalho, consideraremos como capital militante o conjunto de técnicas e saberes que orientam a ação no espaço político e são resultado de uma aprendizagem ocorrida na própria experiência de militância política. O capital político, por sua vez, refere-se a uma forma de capital simbólico, de caráter mais pessoal, fundado na notoriedade e na popularidade, que é, em geral, como o capital cultural, herdado ou concedido a um indivíduo por um determinado grupo, seja a família ou outro grupo social e político, tal como um partido ou sindicato. (Cf: MATONI, F; POUPEAU, F. Le capital militant. Essai de définition. In: Actes de la Recherche - Le capital militant: engagements improbables, apprentissages et techiniques de lute. n. 155, dezembro, 2004 e BOURDIEU, P. A representação política. Elementos para uma teoria do campo político. In: BOURDIEU, P. O poder simbólico. Rio de Janeiro: Bertrand Brasil, 2005.) 
M etalúrgicos do $A B C$ (SM ABC) e o Sindicato dos Trabalhadores em Telecomunicações de São Paulo (Sintetel) ${ }^{3}$. A escolha dos sindicatos não é arbitrária: por um lado, ela se deve ao fato de que ambos vivenciaram processos de transformação na organização dos seus setores em períodos quase concomitantes; por outro, a reestruturação das empresas dos dois setores implicou a renovação dos perfis tanto de trabalhadores quanto de sindicalistas. Acreditamos que esse esforço analítico nos permite lançar luz sobre pontos de contatos exógenos na constituição de práticas militantes, bem como aqueles endógenos, particulares da organização da lógica interna às duas categorias profissionais em questão.

\section{Um sindicalismo do ABC Paulista}

A trajetória do Sindicato dos $M$ etalúrgicos do $A B C(S M A B C)^{4}$ é amplamente conhecida pela sociedade brasileira e está definitivamente associada a imagens que remetem ao período das grandes greves dessa categoria, à emergência de Lula como liderança e à formação do PT (Partido dos Trabalhadores) e da CUT (Central Ú nica dos Trabalhadores). No que tange à condução e à organização do movimento operário, esse sindicato formulou, a partir da onda grevista do final da década de 1970, um modelo de sindicalismo que propunha práticas mais "combativas" ou "radicais", que ficou conhecido como novo sindicalismo. Apesar de alguns autores apontarem os limites desse modelo de sindicalismo, há certa concordância de que tal padrão de ação em muito contribuiu para a renovação da organização dos trabalhadores no Brasil, criando práticas mais eficazes e em consonância com os interesses de seus representados. O s pilares fundamentais do novo sindicalismo eram: a crítica radical aos mecanismos de atrelamento do Sindicato ao Estado; a defesa do direito de greve e da negociação direta entre patrões e empregados, sem ingerência do Estado; a luta pela liberdade e pela autonomia sindical e a organização dos trabalhadores nos locais de trabalho. (Boito, 1992; Santana, 1999).

3. Os dados apresentados neste artigo correspondem à confluência de resultados originados em dois estudos desenvolvidos pelos autores: TOMIZAKI, Kimi. Ser metalúrgico no ABC - transmissão e herança da cultura operária entre duas gerações de trabalhadores. Campinas: Centro de Memória da Unicamp/Arte Escrita Editora; Fapesp, 2007; ROMBALDI, Maurício. Os sindicalistas nas entrelinhas: o caso do Sintetel pós-privatizações. 2007. Dissertação (Mestrado) — Universidade de São Paulo, São Paulo.

4. A primeira formação do Sindicato dos Metalúrgicos da região conhecida como ABC Paulista data de 1933. No período da instalação da indústria automobilística, a entidade desmembrou-se e, em 1959, foram fundados o Sindicato dos Metalúrgicos de São Bernardo do Campo e o de Diadema, que atuaram juntamente com o originário Sindicato dos Metalúrgicos de Santo André. Em 1993 as entidades foram reunificadas por meio da criação do atual Sindicato dos Metalúrgicos do $A B C(S M A B C)$. 
As duas décadas que separam o início das grandes greves dos anos 1990 foram marcadas pela ascensão política do SMABC, de forma que o novo sindicalismo se tornou, por meio da CUT, o projeto sindical hegemônico na década de 1980 entre os principais sindicatos brasileiros. Entretanto, a última década do século XX impôs um conjunto de desafios supreendentes aos velhos sindicalistas do novo sindicalismo, materializado por uma crise - cujo maior sintoma era o fechamento de postos de trabalho - que se abateu sobre o ABC Paulista e que apontava para a possibilidade de transformá-lo na D etroit Brasileira ${ }^{5}$. Em face dessa nova conjuntura regional e nacional, o SM ABC mais uma vez se destacou pela inovação de sua pauta, práticas e estratégias, promovendo experiências inéditas de negociação coletiva e pactação setorial (Rodrigues, 2001; Arbix, 1996).

C omo veremos a seguir, essa nova conjuntura econômica e política, na medida em que alterou profundamente a pauta e atuação desse sindicato exigiu também grandes deslocamentos nos discursos e nas práticas dos sindicalistas. Poderíamos dizer que essas mudanças estiveram orientadas por uma "nova avaliação" dos atributos pessoais e das capacidades estratégicas tidas como desejáveis - ou mesmo aceitáveis - entre as lideranças sindicais.

A vocação para a militância

$N$ a verdadenão sefabrica militantes, né? M ilitantenascefeito! É muito difícil vocêfazer um militante Vocêprepara um militante, vocêinstrui um militante. [...] 0 dirigentesindical elenão œefaz porqueelechega ediz: 'Eu sou!' Eletem queter ação quecombine com o momento, detem quesefazer econhecer, eletem quesefazer respeitar, masnão pela imposição, pela sua humildade, né? Então éuma coisa que, deuma certa maneira, édifícil deseensinar. N ão

5. É importante destacar que a tão mediatizada "crise do $A B C$ " esteve estreitamente associada à forma como o país se inseriu no processo de globalização econômica mundial, já que a abertura econômica e a queda das tarifas alfandegárias tiveram um forte impacto sobre o setor metalúrgico. Por outro lado, a crise da região esteve também vinculada aos custos crescentes de produção gerados pelas chamadas "deseconomias" de aglomeração na região do ABC, geralmente identificadas com o trânsito caótico, as enchentes na época das chuvas, os impostos locais considerados excessivamente altos, as restrições de infra-estrutura, os preços dos terrenos e a regulamentação fundiária, os altos salários pagos aos trabalhadores e a tradição sindical. Entretanto, apesar do sombrio quadro que se formou a partir do final da década de 1980, a década de 1990 assistiu à reação da indústria metalúrgica do $A B C$ que, no ano de 1994, bateu recordes de produção, de produtividade e de vendas, o que afastou o espectro do processo de desindustrialização da região do $A B C$, mas não eliminou o problema da redução dos postos de trabalho. 
seensina, tem queter, a pessoa tem queter o dom, não é? (Entrevista de pesquisa, São Bernardo do C ampo, 2002)

Antôni $0^{6}$, autor do trecho acima, é o autêntico representante de uma geração de militantes que foi "forjada na prática", no cotidiano dos conflitos da fábrica e cuja principal tática de luta era "a confrontação aberta e declarada contra o patrão". Embora essa mesma geração tivesse vivido uma importante experiência de formação política via D epartamento de Formação do SM ABC - de acordo com Antônio, ainda no período em que foi entrevistado - , o que orientava suas ações era a experiência adquirida ao longo da trajetória como sindicalista (Antônio aposentou-se em 2007).

Esse sindicalista chegou a São Paulo em fevereiro de 1967, com 18 anos, vindo de Panelas (PE), onde nasceu e trabalhou na agricultura a partir dos oito anos de idade, bem como seus pais e avós. Embora a família de onze filhos fosse proprietária de um roçado, a seca limitava enormemente as possibilidades da agricultura de subsistência, o que os obrigava a se empregar no trabal ho oferecido pelas usinas de cana-de-açúcar. A experiência migratória desse sindicalista pode ser considerada como das mais difíceis, visto que ele chegou ao Estado de São Paulo quase sem nenhuma rede de apoio: foi o primeiro da família a fazer a migração, não possuía nenhuma qualificação profissional para o trabalho industrial e nem credenciais escolares - os três anos de freqüência à escola em Pernambuco não garantiram sequer sua alfabetização. Assim que chegou a São Paulo, Antônio primeiramente conseguiu empregar-se, em seguida procurou uma escola na qual cursou o supletivo do curso primário, finalizando 0 antigo ginásio em uma escola estadual, ambas no horário noturno.

Antônio "profissionalizou-se" como mecânico de motoresna prática, não tendo cursado, portanto, nenhum tipo de escola profissional. Inicialmente, trabaIhou em pequenas oficinas mecânicas até ser admitido na M ercedes-Benz, em 1974. Alguns anos mais tarde, Antônio entrou em contato pela primeira vez com o Sindicato dos M etalúrgicos, encontro que, de acordo com seu depoimento, alterou radicalmente sua trajetória como trabalhador.

Q uando eu trabalhava em Pernambuco, nasusinas decana, eu na verdadetinha vontadedeencontrar al guém quelutasse pelostrabalhadores E eu, chegando aqui, eu tava na M ercedes, [...] eu já tinha unstrêsanosdeM ercedes Em 77, aproximadamente, apare ceu o Sindicato aqui na porta debaixo edeixou um jornal etrazia uma rèvindicação, queera dos $34 \%$. Q uando eu vi o Lula chegar, eu falè: Puta! Essecara cai u do céu, éo cara quedefendeostraba-

6. Para preservar o anonimato dos depoentes, seus nomes foram trocados. 
Ihadores! [...]. E eu tinha vindo deum momento deexploração, é por isso queeu meemociono. [...] E quando vocêchega aqui evê uma pessoa surgir na porta da fábrica dizendo queessecara tá te explorando [o patrão], vocêprecisa receber isso, vocêvai prestar atenção, foi o queaconteceu comigo! [...] Eu acho queeu tenho que agradecer até de estar vivo. Se não fosse o movimento sindical talvez eu não fossenem vivo! Porque com o estresse, o medo depassar fome, o medo deperder o emprego... Vocêsupera isso! Q uando você adquireconsciência política, vocêperdeo medo!

Por conta da campanha salarial de 1977, que teve grande importância na eclosão das greves do ano seguinte, Antônio pôde conhecer e aproximar-se dos delegados sindicais de base da M ercedes-Benz, cujo trabalho político era bastante limitado pelas práticas generalizadas de repressão ao movimento operário, existentes no período. A partir desse momento, ele passou a compor o grupo de militantes que se propunha a dar continuidade à luta dos trabalhadores no interior da fábrica, após o período das grandes greves (1979-1981). A principal reivindicação desse grupo era que a empresa reconhecesse a Comissão de Fábrica como instância legítima de representação dos interesses dos trabaIhadores, nas palavras dos sindicalistas: "um braço do sindicato dentro da fábrica".

Aqui a gente começou organizando uma militância e eu tava junto com essa mil itância. [...] E a gentecomeçou a fazer algumas reuniões dentro da empresa, pra tentar forçar a $M$ ercedesa ter uma Comissão deFábrica. [...] U m dia nósparamos... N ós paramose fomos atéa sala do Luiz Adelar Schouer, que era o di retor dessa fábrica. [...]. Eledissena época quenósœauto-intitulava representando os trabal hadoresequea gentenão era representanteequede ia mandar todo mundo embora! Aquilo provocou um medo... [...] N ós fomos pro trabalho, criamos uma reivindicação, instrumentamosuma insatisfação dostrabalhadorese paramosa fábrica! Reivindicando salário, uma sériedecoisa, a partesalarial eComissão deF ábrica. 0 Sindicato veio pra medida denegociação eforçou, decerta maneira, a empresa a assumir um compromisso que não demitia nenhum militante, enquanto não tivessea Comi ssão deFábrica. D euma certa maneira nósficamosprotegi dospor aquele compromisso efomospra mesa negociar a Comissão deF ábrica.

Como dito anteriormente, o novo sindicalismo tinha a organização dos trabalhadores nos locais de trabalho como um dos seus princípios. N esse sentido, a luta pela instalação das Comissões de Fábrica por empresa tornou-se uma das principais bandeiras desse movimento. Entretanto, entre aqueles que começaram a trabalhar na organização política dos trabalhadores da montadora após 
as greves, encontrava-se uma maioria de lideranças sem cargos eletivos e que, portanto, vivenciava uma situação de grande vulnerabilidade diante das ações da empresa, que poderia demiti-los a qualquer momento, o que ocorreu em diferentes episódios ao longo dos anos 1980.

$N$ esse sentido, poderíamos dizer que essa primeira geração de lideranças enfrentou uma situação bastante desfavorável, visto que seus membros, além de não possuírem experiências anteriores de militância política, ainda estavam confrontados com uma atitude hostil por parte da empresa. A pesar da falta de experiência, ou mesmo por conseqüência dela, esses militantes, não experimentados nas práticas sindicais ou partidárias, criaram, de acordo com suas necessidades concretas, uma maneira de fazer sindicalismo no interior da fábrica.

D iante de todas essas dificuldades, essa primeira geração de sindicalistas formou-se diante de um duplo desafio: estabelecer sua legitimidade política com os trabalhadores e também diante da empresa. Assim, de um lado, ao longo dos anos 1980, os sindicalistas foram chamados a resolver, de maneira rápida e diante de chefes e gerentes que relutavam em reconhecer a legitimidade dos membros da Comissão de Fábrica, um amplo leque de problemas, que iam das negociações salariais aos problemas do cotidiano fabril. Por outro lado, também precisavam se estabelecer como lideranças diante de trabalhadores cuja expectativa em relação às possibilidades do movimento operário era muito alta nos posteriores ao movimento grevista. Assim, a situação demandava, na maioria das vezes, uma postura combativa e agressiva por parte dos sindicalistas; enfim, uma postura que pudesse, ao mesmo tempo, impor sua existência diante da empresa e criar uma identificação com a base representada.

$\mathrm{N}$ esse momento, é importante atentar para o fato de que o recrutamento dessa primeira geração constituiu-se de uma maneira bastante desorganizada, à medida que os militantes interessados em organizar a luta dos trabalhadores da M ercedes foram se apresentando individualmente ao grupo de delegados sindicais. Entretanto, o que poderia constituir uma fragilidade do processo de recrutamento é interpretado pelos sindicalistas entrevistados como uma espé cie de garantia de que os trabalhadores que se aproximavam deles eram "verdadeiros militantes", dispostos, inclusive, a correr os riscos associados a essa tomada de posição, tal como a perseguição política empreendida pela empresa. Assim, dado que, no período em questão, as desvantagens de ser sindicalistas superavam os possíveis ganhos, aqueles que se apresentavam para militar eram tidos como confiáveis e, mais do que isso, denotavam vocação para a política. $\mathrm{N}$ as palavras dos depoentes, esses trabalhadores possuiriam a "veia política", que não poderia ser criada nem ensinada, mas encontrada em determinados indivíduos que já nasceriam com ela e, diante da sua força, seriam incapazes de resistir ao chamado do engajamento político. 
Grosso modo, poderíamos dizer que a situação de legitimidade da primeira geração está relacionada ao enfrentamento de riscos, à postura de confrontação e à capacidade de intermediar o descontentamento dos trabalhadores. Entretanto, os anos 1990 podem ser entendidos como um período de transformação profunda das condições de possibilidade de se construir a legitimidade no interior do movimento sindical do ABC. A chamada reestruturação produtiva impôs aos sindicalistas problemas e dificuldades totalmente novas, que exigiram também respostas inovadoras, muitas vezes radicalmente diferentes daquelas que caracterizavam a ação do novo sindicalismo. No caso da M ercedes, o projeto de modernização apresentado pela montadora, em 1992, impulsionou a entrada da Comissão de Fábrica em uma nova fase, cujo foco principal passou a ser o processo de negociação das transformações da organização do trabalho, com vistas à minimização dos seus efeitos negativos.

Essa nova fase levou o SM ABC a redefinir seus investimentos na formação de quadros, dando grande destaque a cursos e intercâmbios internacionais, tendo em vista preparar as lideranças para essa nova forma de atuação política. Evidentemente, essa transformação na prática da Comissão de Fábrica da M ercedes também exigiu novos conhecimentos e atributos dos sindicalistas, fazendo com que a correlação de forças no interior do próprio grupo se alterasse. 0 resultado foi uma situação na qual os sindicalistas mais jovens, que contavam com mai or capital escolar, assumiram pouco a pouco uma posição de destaque. Poderíamos dizer que o capital escolar foi convertido em um novo tipo de capital militante, não mais baseado na força física, no carisma ou na capacidade de confrontação, mas na capacidade de argumentação, leitura e resolução de cál culos matemáticos; na boa articulação em reuniões com a empresa; na elaboração de propostas, etc. D e acordo com as entrevistas e as observações, podemos afirmar que alguns antigos sindicalistas, desprovidos desse capital escolar, não conseguiram manter as posições que ocupavam no interior da Comissão de Fábrica no período anterior, enquanto outros procuraram redefinir suas ações e estratégias para adequar-se à nova configuração do campo sindical, como Antônio.

Eu acho que, de uma certa maneira, nóstambém abandonamos um pouco o radicalismo, né?[...] N ósnão podemosimpedir a empresa desemodernizar. E nósnão podemosnegar quea conjuntura mundial leva o Sindicato a tentar se enquadrar, a modernizar também. Eu estive na Alemanha, a M ercedes levou a gente pra Alemanha pra ver o trabalho em grupo. [...] E vocêsó passa a ser respeitado na fábrica também, quando vocêtambém respeita. Então, setudo queacontecena fábrica, vocêvai parando [paralisando a produção] éporquevocênão tem diálogo com a empresa, sea empresa abrecanaisvocênão vai parar tudo [...]. Sóquevocêsófaz 
i sso quando vocêtem o poder dedomínio da s tuação, quando você não tem, quando vocééhumilhado, vocêradicaliza, nãoé?

Além das transformações ocorridas nas práticas cotidianas dos sindicalistas, Antonio acredita que a própria condição de sindicalista se alterou nos últimos anos. D e acordo com seu depoimento, a participação político-sindical de uma situação de alto risco passou a uma situação que pode garantir desde estabilidade no emprego até uma série de vantagens, tais como afastamento do trabaIho da fábrica, possibilidade de viajar e participar de diversos cursos oferecidos pelo sindicato, inclusive de línguas estrangeiras. Essas transformações nas condições do trabalho de representação impõem, em certo sentido, uma barreira na relação entre as diferentes gerações, visto que essas acabam por estabelecer uma relação de desconfiança entre os antigos e os novos militantes. D e acordo com o depoimento de Antônio, a dúvida que o incomodava era se o novo militante, quando se apresentava como candidato a cargos representativos, estava, de fato, interessado no trabalho sindical ou, sobretudo, nas vantagens que esse engajamento poderia oferecer-lhe.

$\mathrm{N}$ esse cenário, poderíamos dizer que os velhos sindicalistas - desprovidos do capital militante atualmente valorizado e que poderia garantir-Ihes uma situação de legitimidade - acusam aqueles que começam a despontar como lideranças de não possuir a "verdadeira vocação política", tentando, assim, maximizar o valor das que caracterizaram "o seu tempo". A mesma tendência poderá ser observada no caso do Sintetel, que poderá ajudar-nos a avançar mais nas reflexões propostas por esse artigo.

\section{Um sindicalismo sob a privatização das telecomunicações}

Olha, tem uma coisa que eu aprendi no meio sindical. Tem um determinado momento em queeu tenho dificuldadeem ponderar, sabe?! N ão sei seisso ébom ou ruim, maseu sou um pavio curto, quando o bicho pega, eu perco a razão. Eu aprendi um tipo deluta que não seaplicava para estemomento. (0 svaldo, 2006).

As palavras de 0 svaldo, presidente do Sintetel nos dez anos subseqüentes a 1987, exprimem o desajuste sentido entre as práticas por ele adotadas na época em que ainda militava como sindicalista e o padrão de ação sindical que se desenvolveu a partir da privatização das telecomunicações, no final dos anos 1990. A reflexão sobre a militância da época, recorrentemente conjugada em primeira pessoa, demonstra não apenas o caráter personalista de sua fala, mas também indica o caráter exemplar e prescritivo do discurso de um sindicalista que se auto-avalia vitorioso. Refere-se a um dever ser na condução da militância 
sindical e, ao mesmo tempo, deixa transparecer certa ambigüidade, que reside na oscilação entre o sentimento de orgulho e o de frustração por não mais poder conceber a sua forma de agir como ideal diante da nova conjuntura apresentada pelas transformações decorrentes da privatização das telecomunicações: em outras palavras, a valorização de sua trajetória é acompanhada da resignação diante da percepção de que o seu tempo no sindicato terminou.

A trajetória deste sindicalista é elucidativa no que corresponde à íntima relação entre as transformações das estruturas sociais - e entre elas a econômica - e as transformações das práticas sociais. Como fio condutor que possibilita a visualização do ponto de partida, do processo e do fim de uma carreira militante, o percurso social deste militante permite apreender como determinantes fatores tais como a origem social, a composição do mundo do trabalho e as formas de sociabilização que influenciam na emergência e no destino de práticas militantes. Assim, neste trabalho, assumimos o desafio de analisar a articulação entre a trajetória de 0 svaldo e o processo de constituição de suas práticas sindicais por meio de diferentes elementos, sendo eles: (i) a trajetória do sindicato de telecomunicações de São Paulo; (ii) o tipo de relações sociais existentes no trabalho no setor de telecomunicações; (iii) os lugares sociais ocupados pelos trabalhadores/sindicalistas desse setor.

O Sintetel é originário da então chamada Associação Profissional dos TrabaIhadores em Empresas Telefônicas do Estado de São Paulo, transformada em sindicato em 1941. Desde a fundação do sindicato, até o início da abertura democrática na década de 1980, sob os regimes repressivos de Getúlio Vargas e dos militares, a entidade caracterizou-se, sobretudo, por um sindicalismo de tipo assistencialista. Segundo Rubens Biasi, presidente do sindicato entre os anos de 1969 e 1981, as ações do sindicato eram marcadas, principalmente, por realizações na área social, tais como a aquisição de terrenos para a construção de colônia de férias.

Em certa medida, pode-se dizer que as práticas sindicais nas telecomunicações, até meados da década de 1980, caracterizavam-se, essencialmente, por funções administrativas e burocráticas e pelo pouco enfrentamento frente à gerência da Telesp quanto aos temas de remuneração e de outros direitos sociais. Entretanto, em função das transformações conjunturais que se espal havam pelo país, sobretudo com o movimento pela abertura democrática e 0 fim da repressão política - o que incluía as manifestações pelo fim da intervenção nos sindicatos - , estes passaram a vivenciar as possibilidades de exercer um sindicalismo de tipo reivindicatório. Segundo o jornal do Sintetel, Linha Dire ta, de 1992, foi o tempo em que teve início um movimento de mobilização grevista por reposições salariais, durante 0 qual o sindicato aumentou as visitas aos locais de trabalho e incrementou cursos de formação sindical, bem como 
foi possível observar o ingresso de novos dirigentes em substituição aos antigos, originários do período militar.

Essa foi a época de aproximação de 0 svaldo com o sindicato. N esse momento, desenvolveu-se um primeiro movimento de renovação dos quadros do sindicato a partir da unificação das chapas concorrentes a sua diretoria, agregando dirigentes provenientes de correntes políticas opostas, tais como dirigentes filiados à então recente Central Ú nica dos Trabalhadores, fundada por sindicalistas identificados com o Partido dos Trabal hadores e dirigentes simpáticos ao M R-8, PC do B e PCB. D ois anos mais tarde, o sindicato afiliar-se-ia à recém-criada $C$ entral Geral dos Trabalhadores.

No final dos anos 1990, no último mandato desse sindicalista na presidência da entidade, os ares no sindicato transformaram-se: a privatização ocorrida em 1998 era pedra angular de tal mudança. A reestruturação do setor foi impulsionada pelo surgimento de novas tecnologias, que tornaram os sistemas de transmissão mais baratos, despertando o interesse de possíveis competidores em um mercado em que se destacava a existência de uma demanda não atendida pelos serviços de telecomunicações (Larangeira, 1998). Um resultado direto de tal processo, para além das transformações na organização do setor, foi a significativa alteração no perfil dos trabalhadores ${ }^{7}$, agora geograficamente dispersos devido à fragmentação das empresas estatais. Em um período em que tanto o perfil dos trabalhadores representados como as empresas com quem negociavam haviam se modificado, para o sindicato, surge a questão: a forma de fazer sindicalismo também deveria transformar-se? U ma pista para essa resposta foi o encerramento de carreiras de uma geração de sindicalistas da qual O svaldo fazia parte.

Para essa geração, que ingressou na Telesp e no Sintetel durante o período que antecedeu o processo de privatizações, a conquista da vaga na estatal de telecomunicações paulista tinha um sentido ainda maior do que a mera condição de subsistir fora de sua terra natal. 0 trabalho na empresa significou a importância do estabelecimento bem sucedido em terras desconhecidas, a constituição de elos de sociabilidade e de laços de identidade entre trabalhadores e,

7. Dados obtidos por meio da RAIS-CAGED permitem afirmar que, sobre o total de ocupações no setor de telecomunicações brasileiro, o número de trabalhadores com mais de 40 anos reduzse de $42 \%$, em 1998, para $24 \%$ no ano de 2002, ao mesmo tempo que os trabalhadores com idade entre 18 e 24 anos duplica de 13\% para 26\%, no mesmo período. Observa-se também que a remuneração do trabalhador em telecomunicações decai, já que, em 1998, após a privatização, diminui significativamente o número de trabalhadores com remuneração superior a I 5 salários mínimos: de 30\% em 1998, observa-se esse número decair para 20\% em 2002; ainda, nota-se a concentração de trabalhadores com remuneração inferior a 2 salários-mínimos, dado que a porcentagem de trabalhadores com tal remuneração passa de 5\% em 1998 para $19 \%$ em 2002. 
mesmo que de forma ambígua, entre eles e a empresa. Além disso, a entrada na Telesp era recoberta por uma distinção social materializada em prestígio, fato recorrentemente expresso nos depoimentos coletados entre sindicalistas, em que se dizia que "ao entrar na Telesp, você engordava, casava, ou comprava um carro" ou que "ao entrar em uma loja com vendas a crédito, bastava mostrar 0 crachá de funcionário que sequer necessitava preencher um cadastro de cliente, dada a confiança que se tinha em quem trabalhava na estatal".

0 perfil dos trabalhadores que se tornaram dirigentes do Sintetel até a primeira metade da década de 1990 era semelhante: em grande parte migrantes de primeira geração, filhos de pais com pouca escolarização; além disso, esses trabalhadores tinham sua formação profissional resumida basicamente aos cursos promovidos pela própria Telesp.

Com isso, a estatal fornecia não apenas emprego, mas também a formação escolar necessária para o desempenho das atividades na empresa. Até meados da década de 1990, a Telesp estabelecia convênios com o Serviço N acional de Aprendizagem Industrial (Senai) para a especialização de trabalhadores como O svaldo. D esde o final dos anos 1960, a empresa contava com centros de treinamento em prédios com professores e equipamentos para a formação dos recém-contratados ${ }^{8}$. Para estes, tal aperfeiçoamento técnico obtinha contornos de uma formação adquirida por meio do trabalho cotidiano, o que fazia com que os conhecimentos adquiridos na prática ganhassem grande importância: a formação escolar constituía-se nas atividades dentro da empresa, e não fora dela.

O svaldo, ex-presidente do Sintetel, pode ser considerado um caso exemplar da sua geração. N ascido em 1947, ingressou na Telesp em 1966 e sabe na ponta da língua o tempo dedicado ao trabalho nas telecomunicações: 33 anos no setor, 18 na Telesp e 15 no sindicato. Filho de pais apenas alfabetizados, migrante vindo do interior de São Paulo para a capital, trabalhou como técnico de rede e, com o passar do tempo, galgou o cargo de supervisor de projetos, após realizar os cursos de formação promovidos pela empresa. Enquanto desempenhava funções de empregado da Telesp, cursou a faculdade de direito entre os anos 1979 e 1984, tendo concluído a graduação em direito pouco tempo antes de ingressar na diretoria do sindicato. Em suas palavras: "na dire toria do sindicato é mais difícil de seguir uma carreira acadêmica, pois, ali, não temos tempo para mais nada".

O svaldo está longe daquele gélido perfil que se espera de um técnico: usa uma barba espessa com o mesmo tamanho dos tempos em que era presidente

8. Na década de 1980, na Telesp, à exceção das funções estratégicas que eram ocupadas por trabalhadores com formação universitária, a formação em nível superior ainda não se constituía como pré-requisito para a contratação de novos trabalhadores. 
do sindicato, agora, entretanto, com a preponderância da cor branca. Formouse em direito com ênfase no entendimento sobre a legislação trabalhista; entretanto, faz questão de dizer que nunca exerceu a profissão de advogado. Para ele, a formação universitária foi muito importante na sua trajetória no sindicato, porém, o conhecimento adquirido na universidade serve menos como instrumento para um tipo de militância identificada com aqueles conhecimentos técnicos que permitiriam "propor alternativas" e mais para uma forma relativamente defensiva de militância: a sua formação escolar servia como antecipação das "rastei ras pregadas pelo patrão". O significado da militância e do que era bom para os trabalhadores vinha das lições aprendidas no meio familiar, "vinha de sangue".

$\mathrm{N}$ o depoimento de $\mathrm{O}$ svaldo, eram recorrentes os apelos morais que justificavam a forma de agir dos militantes do seu tempo. Ele vincula os seus aprendizados para a prática política aos valores transmitidos nas suas redes de relações sociais. D estaca, sobretudo, a esfera familiar e aqueles ensinamentos proferidos por seu pai, um ex-militante sindical que trabalhou em uma fábrica de papel no interior de São Paulo. Segundo seu depoimento:

O svaldo - Ele [o pai] tinha essa questão queeu semprefalo pro pessoal, (tá entendendo?!), de queo patrão nunca vai precisar estar próximo do sindicato [...]. Eu já fui vacinado na minhaconvivência familiar contra o 'peleguismo'.

M aurício - M aso queéesta vacina?

0 svaldo - Esta vacinaéquando vocêvai numa negociação e não há chances de vocêse entregar, devocêser seduzido pelo patrão.

Como demonstrado no trecho acima, esse militante sindical possui um forte apego ao saber prático, pois nele está valorizado não somente o percurso profissional na Telesp que, nas suas palavras, representa uma "carreira muito boa", mas também a sua experiência como sindicalista: ao longo de sua trajetória como líder sindical, realizou cursos e conheceu colegas em países como Itália, Estados U nidos e I srael. N essas experiências internacionais é que aprendeu a falar com certa improvisação o italiano e o espanhol.

O svaldo foi presidente do diretório acadêmico de sua faculdade, onde, segundo ele, teve as primeiras lições externas ao seio familiar sobre "como era militar". A partir disso e do exercício da função de colaborador do sindicato é que vieram os convites para ingressar em outros postos na hierarquia da entidade. Era um momento em que o movimento habitual para se tornar um sindicalista correspondia a, primeiramente, tornar-se um colaborador sindical, depois, delegado e, em seguida, diretor. Segundo o depoimento de sindicalistas dessa geração, naquele período havia poucas vagas para participar da composi- 
ção da chapa vencedora das eleições do sindicato em relação ao grande número de pessoas interessadas no trabalho sindical'.

Até a privatização da Telesp, a história de sindicalistas que consolidavam laços sociais com base na linearidade e na semelhança de trajetórias sociais, bem como em vínculos estabelecidos no cotidiano do trabalho, era o que permitia serem reconhecidos como "um de nós": a semelhança entre origem e destino, entre necessidades e conquistas realizadas; tornava as práticas militantes relativamente previsíveis. A pós a reestruturação das telecomunicações, essas referências mais ou menos estáveis tranformam-se lado a lado com as mudanças no perfil tanto das empresas quanto de trabalhadores e sindicalistas.

Se, por um lado, pode-se dizer que as inovações sentidas no Sintetel até a privatização da Telesp tinham uma relação mais profunda com as alterações no campo propriamente político do que no econômico, por outro, após o final dos anos 1990, a influência do campo econômico foi decisiva nas transformações que dizem respeito à forma de fazer sindicalismo.

A partir da privatização da Telesp em 1998 e da decorrente substituição do interlocutor do sindicato - de um administrador estatal para diversos administradores no campo privado - , a militância nas telecomunicações foi desafiada pela necessidade de realizar acordos coletivos em grande escal $a^{10}$, de partiIhar mesas de negociação com executivos de empresas multinacionais e, também, de representar trabalhadores que vivenciavam uma realidade bastante distinta daquela a que os sindicalistas estavam acostumados até então. 0 domínio de idiomas estrangeiros e uma postura "racional" passaram a ser valorizados na mesma medida que os erros de português e a passionalidade nas mesas de negociação tornavam-se sinônimos de constrangimento social.

Com isso, as transformações quanto ao que esperar de sindicalistas em seu trabal ho de representação estavam intimamente vinculadas aos símbolos historicamente constituídos por meio das relações de trabalho. Em um primeiro momento, uma série de símbolos de valorização social representou a possibilidade do reconhecimento da liderança sindical como pertencente ao "ele é um de nós, é igual e quer a mesma coisa que queremos". Seriam eles: a conservação de

9. Após a privatização da Telesp e a subseqüente ampliação do número de sindicalistas que compunham a chapa eleita, resultado da necessidade de ter sindicalistas em número suficiente para trabalhar no expandido setor de telecomunicações, o caráter processual e gradativo na ascensão sindical nas telecomunicações se rarefaz. Conforme observa ROMBALDI (2008, p. 196-200), o quadro de dirigentes passa a contar com maior número de jovens provenientes de empresas de tele-atendimento e de mulheres, ambos sem um histórico de trabalho no setor ou necessidade de experiência militante prévia.

10. Para ilustrar o expressivo crescimento do número de empresas com quem o Sintetel negocia acordos coletivos: atualmente o sindicato conta com cerca de 136 acordos firmados somente no Estado de São Paulo. 
sentimentos de valorização (a) do emprego e da formação adquirida por meio dele, (b) do reconhecimento social concedido ao trabalhador da estatal, (c) do relacionamento com os colegas de trabalho ao longo dos anos, (d) da possibilidade de planejar promoções internas na empresa. Tais elementos implicaram a possibilidade da constituição de semelhantes expectativas e previsões sobre as futuras trajetórias sociais. $M$ ais que isso, pode-se afirmar que eles representaram um caráter mais ou menos homogêneo sobre os referenciais simbólicos que orientaram as práticas desses sindicalistas. N o momento seguinte, emergiu a complexidade das telecomunicações e a fragmentação de caracteres estáveis à sociabilidade no setor, emergiu a valorização da competência técnica como critério de avaliação do "bom militante" ou "bom sindicalista".

O svaldo saiu do sindicato em 1997. D e sua parte, não houve resistência. D e acordo com seu depoimento, esse movimento ocorreu em função do reconhecimento de que os tempos no sindicato haviam mudado, e com essas mudanças o seu tempo no movimento sindical havia se esgotado. Ele já não conseguia negociar com essa nova realidade. Tal desalento representa uma valorização deslocada. U ma legitimidade que teve o seu momento, mas que agora não encontra os mesmos interlocutores, sejam eles trabalhadores ou patrões. Para esse sindicalista, são tempos para que novas lideranças e práticas sindicais sejam criadas - ainda que não se saiba exatamente o que isso possa tornar-se.

Por fim, para os sindicalistas do presente, tempos difíceis rondam a vista. A formação dos referenciais que orientarão os militantes encontrará a dificuldade de conviver com as irregularidades que o emprego instável e temporário proporciona. Soma-se a isso a diminuição dos salários, que contribui para a desvalorização do emprego e de si mesmo. Os laços sociais estabelecidos com outros colegas de trabalho já não têm o mesmo tempo para atarem-se e já há margem para que os próprios trabalhadores do presente não encarem o trabalho nas telecomunicações do mesmo modo que os do passado: símbolo da ampliação das telecomunicações pós-privatizações — já que compreende o maior número de trabalhadores no setor -, o emprego em call centers comumente é apenas uma porta de passagem, um vínculo temporário existente para que trabalhadores encaminhem outros projetos pessoais. Se o tempo presente e as expectativas para o futuro são cada vez menos lineares, provavelmente assim também será para a constituição de novos militantes.

\section{Considerações finais}

0 que se tem convencionado denominar de militantismo designa um conjunto de fenômenos altamente complexos e multifacetados, cuja compreensão pede uma análise multidisciplinar. D esse modo, o estudo do engajamento políti- 
co exige daqueles que se propõem a fazê-lo um diálogo ativo entre as ciências sociais, a psicologia e também com a área da educação, na medida em que os processos de socialização parecem definidores das condições de possibilidade do surgimento de práticas de militância política. Essas são as premissas que fundamentaram o exercício intelectual que resultou neste artigo. Assim, analisamos prioritariamente as práticas dos sindicalistas e como essas podem redundar ou não na constituição de uma situação de legitimidade. Para tanto, foi necessário discutir a noção de "vocação para a política", fundamental para os sindicalistas na constituição de esquemas de percepção que hierarquizam os indivíduos que pertencem a esse espaço político.

A partir dos casos aqui apresentados, podemos afirmar que a chamada reestruturação produtiva dos setores metalúrgico e das telecomunicações teve um forte impacto na definição e redefinição das práticas e estratégias sindicais que podem ser consideradas legítimas. Isso significa dizer que a reorganização social do trabalho, na medida em que altera sua relação com o capital e também com o Estado pode conduzir a alterações nos modos de conceber o papel dos sindicatos e, conseqüentemente, nos quadros de referências cognitivas e afetivas dos militantes. Entretanto, voltamos a afirmar que tal movimento não pode ser observado com a mera descrição das transformações nas práticas institucionais dos sindicatos. $M$ ais que isso, os processos de engajamento na vida sindical ou de construção das legitimidades no meio político não são 0 resultado de escolhas estritamente racionais, de cálculo sobre custos e benefícios desse empreendimento. Antes, respondem a um silencioso chamado que resulta da articulação entre relações sociais objetivas e subjetivas ou, nas palavras de Bourdieu em crítica a M ax Weber: "o reconhecimento da legitimidade não é [...] um ato livre da consciência esclarecida", mas "ela se enraíza no acordo imediato entre estruturas incorporadas [... ] e estruturas objetivas". (Bourdieu, 1996).

D e acordo com Pudal (2003), o que é nomeado como vocação pelos militantes resulta de um processo interativo complexo entre a história social pessoal do indivíduo e a instituição "reconhecedora", um processo feito de transações permanentes, no qual se trocam "dons" e "contra-dons" em uma negociação contínua. Assim, em contrapartida ao "dom", de caráter individual, existe 0 trabalho da instituição - leia-se dos agentes que ocupam um lugar privilegiado no interior de determinado espaço político - que procura verificar a autenticidade e a qualidade da vocação. 0 que procuramos demonstrar neste artigo é o fato de que, em períodos de aceleradas transformações estruturais, os quadros de percepção e avaliação dos aspectos que podem ou não ser considerados como indicativos da vocação para a política ou da legitimidade também se tranfformam, causando uma situação de dolorosa vulnerabilidade para al- 
guns indivíduos, ou mesmo para gerações inteiras. Tais mudanças influenciam diretamente o conjunto do trabalho sindical, ou seja, suas práticas, suas estratégias, seus discursos e, sobretudo, a definição dos sujeitos que farão parte desse espaço. Essa constatação aponta para a necessidade de um investimento, por parte dos estudiosos do sindicalismo, na constituição de uma "sociologia da vocação", capaz de ultrapassar as barreiras disciplinares, tendo em vista a compreensão dos processos de recrutamento e formação das lideranças no movimento operário. Assim, este artigo, menos do que um texto definitivo a respeito desse assunto, constitui um conjunto de reflexões que orientam um plano de trabalho assumido pelos seus autores nos últimos anos, com o objetivo central de conduzir nessa direção suas pesquisas sobre 0 sindicalismo.

\section{Referências bibliográficas}

ARBIX, G lauco. U ma aposta no futuro. O sprimeirosanos da C âmara Setorial da Indústria Automobilística. São Paulo: Scritta, 1996.

BO ITO Jr., Armando (O rg.). 0 sindicalismo brasileironosanos80. Rio de Janeiro: PazeTerra, 1992.

BO U RDIEU , Pierre. Réponses. Paris: Seuil, 1992. (Avec Loïc Wacquant).

BO U RD IEU , Pierre. Razõespráticas. C ampinas: Papirus, 1996.

BO U RD IEU , Pierre. A representação política. Elementosparauma teoriado campo político. In: BO U RDIEU , Pierre. 0 poder simbólico. Rio deJ aneiro: Bertrand Brasil, 2005.

CAN ED 0 , Letícia. La production généalogiqueet les modes detransmission d'un capital politiquefamilial dansleM inas G erais brésilien. Genèses, Paris, n. 31, juin. 1998.

CAN ED 0 , Letícia. Estratégias familiares na construção social de uma qualificação política. Educação eSoci edade, C ampinas, ano 12, ago. 1991.

CAN ED 0 , Letícia. H eritageem politique, ou comment acquerir les dispositionset competences necessaires aux fonctios de representations politique (1948-1964). Cahiers du Brésil Contemporain, Paris, n. 47-48, 2002.

LARAN GEIRA, Sônia M. G. Reestruturação no setor de telecomunicações: inovações tecnológicas, privatização e desregulamentação: aspectos da experiência internacional. Revista Latinoamericana deE studios del Trabajo, ano 4, n. 8, p. 159-178, 1998.

M ATO N I, F.; PO U PEAU , F. Lecapital militant. Essai de définition. Actesdela Recherche- Le capital militant: engagementsimprobables, apprentissages et techiniquesdelute. Paris, n.155, dez. 2004.

OFFERLÉ, M ichel. La profession politique- XIX - XX sièdes Paris: Belin, 1999.

O LSO N , M ancur. A lógica da ação coletiva: os benefícios públicos e uma teoria dos grupos sociais. São Paulo: Edusp, 1999. 
PUD AL, Bernard. PrendreParti - Pour une sociologiehistoriquedu PCF. Paris: Presses dela Fondation N ationale des Sciences Politiques, 1989.

PU D AL, Bernard. La vocation communistee ses récits. In: LAG RO YE, Jacques. (0 rg.) La politisation. Paris: Belin, 2003.

RO D RIGUES, Iram Jácome. (0 rg.). 0 novo indicalismo - vinteanosdepois. Petrópolis: Vozes; São Paulo: Educ, 1999.

RO D RIGUES, I ram Jácome. U m laboratório das relações de trabalho: 0 ABC paulistanos anos 90. In: EN CON TRO AN U AL D A AN PO CS, 25., 2001, Caxambu. SeminárioTemático: "Trabalhadores, sindicato ea nova questão social." C axambu, 2001.

RO D RI GU ES, Leôncio M artins. D estino do sindicalismo. São Paulo: Edusp, 1999.

ROM BALDI, M aurício. M udanças, continuidadese descompassosentreo mundo do trabalho e o perfil das lideranças sindicais em telecomunicações. Revista de D ireito do Trabal ho, São Paulo, v. 130, p. 182-201, 2008.

SAN TAN A, M arco Aurélio. Entrearupturaea continuidade: visões da história do movimento sindical brasileiro. Revista Brasileira deCiências Sociais, São Paulo, v. 14, n. 41, 1999.

SAN TAN A, M arco Aurélio; RAM ALH O , JoséRicardo. (O rg.). Além da fábrica: trabalhadores, sindicatose a nova questão social. São Paulo: Boitempo, 2003.

T O M IZAKI, Kimi. Ser metalúrgico no ABC - transmissão eherança da cultura operária entre duas gerações de trabal hadores. C ampinas: Centro de M emória da U nicamp; ArteEscrita; Fapesp, 2007.

WAG N ER, Anne-Catherine. Syndicalisteseuropéens: les conditions socialeset institutionnelles del'internationalisation des militants syndicaux. Actesdela rechercheen sciencessociales, Paris, $\mathrm{n}$. 155, 2004.

WAG N ER, Anne-C atherine. Vers une Europe syndicale. Une enquête sur la confédération européenne des syndicats. Paris: Croquant, 2005. (Savoir/Agir).

Recebido em 31 deoutubro de2008 eaprovado em 06 demarço de2009. 